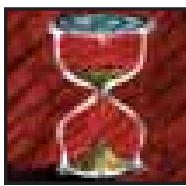

\title{
Quarterly Change
}

In British Columbia, 11 members have been appointed to the Emergency Health Services Commission to guide the delivery of high-quality, consistent pre-hospital emergency healthcare. The commission provides strategic direction and governance to the B.C. Ambulance Service. The new members will further strengthen ambulance services and encourage more integration with the six health authorities to develop a better continuum of pre-hospital care. The expanded makeup of the commission provides balanced representation from government and the health authorities as well as from key leaders with medical and clinical expertise. The new appointments are: Bert Boyd, Chair; Dr. David Butcher, Northern Health Authority; Dr. James Christenson, Vancouver Coastal Health Authority; Dr. Jeff Coleman, Vancouver Coastal Health Authority; Dr. Urbain Ip, Fraser Health Authority; Joanne Konnert, Fraser Health Authority; Dr. Glen Lowther, Vancouver Island Health Authority; Dr. Patricia Petryshen, Ministry of Health Services; Dr. Brian Schmidt, Provincial Health Services Authority; Anne Sutherland Boal, Ministry of Health Services; and David Woodward, Ministry of Health Services.

The commission representative for the Interior Health Authority will be named shortly.

Also, a new CEO was recently named to the B.C. Ambulance Service. David Morhart was appointed on Feb. 9, 2004. He replaces B.C. Ambulance Service Executive Director Paul Gotto, who is retiring.

Emergency Health Services Commission members' biographies are available at www.gov.bc.ca/healthservices.

In Alberta, the cost of basic health services increased in 2002/2003, while more lower-income Albertans paid reduced healthcare premiums or were exempt from paying them according to the 2002/2003 Alberta Healthcare Insurance Plan Statistical Supplement. The supplement is an annual update of statistics relating to the plan, which covers Albertans for services provided by physicians and other health practitioners.

Highlights of the 2002/2003 Statistical Supplement include:

- $\$ 1.2$ billion was paid to physicians for basic health services, an increase of more than $\$ 164$ million, or $15.5 \%$ over $2001 / 2002$.

- More than three million Albertans were covered by Alberta's healthcare insurance plan, an increase of more than 52,000 people, or $1.7 \%$.

- 474,084 Albertans were fully exempt from paying healthcare premiums. Overall, $16.9 \%$ of the Alberta population paid reduced or no premiums, an increase of 5,900 .

- The average annual payment to physicians was $\$ 235,426$, an increase of $\$ 26,493$, or $12.7 \%$.

- 220 physicians received a total annual payment of under $\$ 10,000$, and 61 received more than one million dollars in payments.

- The average annual payment to specialists was $\$ 288,969$, an increase of more than $\$ 36,000$, or $14.3 \%$.

- 323 specialists received a total annual payment of more than $\$ 500,000$, which represents $13.8 \%$ of specialists.

The 2002/2003 Alberta Healthcare Insurance Plan Statistical Supplement is available online at www.health.gov.ab.ca.
In Saskatchewan, the health budget has an overall increase of $\$ 160$ million or $6.3 \%$. This will allow the vast majority of programs to continue and strategic investments to occur, but some system change will be required. Health spending now accounts for $44 \%$ of provincial program spending. Funding increases for regional health authorities range from 3.6 to $6.6 \%$, with the larger increases targeted in those regions operating provincial hospitals. Although these are significant increases, changes in health delivery are required and will include further administrative efficiencies, changes in staff mix, facility closures or conversions and reductions in long-termcare bed numbers. Saskatchewan Health will be working closely with regional health authorities to finalize the regional plans in the coming months.

Saskatchewan has unveiled a key initiative in its strategy to better manage surgical access. "Target Time Frames for Surgery" will help patients receive surgical care according to their level of need. It is another significant action for improving timely access to surgical care, identified as a priority in the Action Plan for Saskatchewan Healthcare. Target Time Frames are performance goals set for all surgical specialties and procedures. These targets will allow the surgical care system to better monitor and track patients and help to ensure they receive care according to their level of need.

Saskatchewan Health will work with health regions to concentrate on two key areas. The first key area will be cancer surgeries. Reflecting their urgency, the goal will be to complete $95 \%$ of cancer surgeries within three weeks. The other key focus will be on patients who have been waiting longest for surgery. The target is to have all surgeries completed within 18 months. For information on SSCN initiatives, visit www.sasksurgery.ca. 
In Manitoba's recently released 2004 budget saw the health budget increase $5.2 \%$ to $\$ 3.2$ billion. Of note - acute care is getting a $6.5 \%$ boost while long-term care is receiving $2.7 \%$ extra and home care $1.6 \%$. The physician services budget is up $7.5 \%$ to $\$ 577.8$ million, while the pharmacare budget is being increased by $3.3 \%$ to $\$ 177.5$ million.

The budget also provides specific funds to increase the number of heart surgeries, and provide more staff in emergency rooms to reduce wait times - two issues that have plagued the government in the past year. Funds are also being made available to educate more nurses and expand Manitoba's two-year nursing diploma program. Licensed practical nurses in rural areas will be given the opportunity to train to become registered nurses. Nurses who want to return to work will receive assistance to refresh their skills.

In Ontario, Health and Long-Term Care Minister George Smitherman recently released the interim report from Commissioner Archie Campbell on the investigation into the outbreak of Severe Acute Respiratory Syndrome (SARS) in Ontario and announced a timetable for a comprehensive action plan on public health renewal. The Campbell report recounts how decades of problems and inaction in public health contributed to the SARS crisis.

Smitherman said there is more work to be done and he will release a comprehensive action plan for public health in two months, which will look at:

- Public health leadership and accountability

- Creation of a health protection and promotion agency for Ontario

- Legislative changes to increase the independence and strengthen the role of the Chief Medical Officer of Health

- Health emergency preparedness

- Expanded health human resources

For a copy of the Campbell report, visit www.health.gov.on.ca.

The Registered Nurses Association of Ontario (RNAO) has announced new partnerships with two Quebec healthcare organizations to implement and evaluate nursing best-practice guidelines (NBPG). The two spotlight organizations are Hôpital Charles LeMoyne and McGill University Health Centre, bringing the total number of RNAO NBPG spotlight organizations to nine: Hôpital Regional de Sudbury Regional Hospital; Niagara Health System; Royal Victoria Hospital (Barrie); Saint Elizabeth Healthcare (across Ontario); University Health Network (Toronto); Victorian Order of Nurses, Canada/VON Peterborough Victoria Haliburton; and West Park Healthcare Centre (Toronto).

To date, Ontario's NBPG Project, led by RNAO and funded by MOHLTC, has completed 21 guidelines focusing on elder health and elder care, home healthcare, mental healthcare, emergency care and primary healthcare as well as an implementation toolkit to help nurses and organizations use the guidelines. And development of four new guidelines is in progress. Health education fact sheets have been developed to supplement the guidelines and increase the public's knowledge and involvement in making decisions about their health. Thousands of expert nurses from across Ontario and all sectors of the profession - staff nurses, advanced-practice nurses, researchers, administrators, academics and policy experts - have been developing, pilot testing, implementing and evaluating guidelines that flow from the latest research in nursing practice.
On April 23, 2004 the Ross Tilley Burn Centre (RTBC) at Sunnybrook \& Women's College Health Sciences Centre (S\&W) officially celebrated 20 years of groundbreaking burn care. The RTBC is named in honour of Dr. Ross Tilley, a former reconstructive plastic surgeon at the Wellesley Hospital where the burn centre officially opened its doors. At the Wellesley Hospital, it operated with only seven tertiary-care beds. In 1998, as part of the healthcare restructuring, the Centre was transferred to Sunnybrook \& Women's. Since moving to Sunnybrook \& Women's, RTBC has grown into a state-ofthe-art facility, the largest of its kind in Canada. The Electrical Burn

Telemedicine Program and the Office of International Surgery are two examples of how the centre has been able to reach out to help burn patients in clinics across Canada and as far away as Uganda and China. For more information on the RTBC, visit them at www.sw.ca/RTBC.

A review of plans for two new superhospitals in Montreal has found they are both likely to run significantly over budget. The review, conducted by former Prime Minister Brian Mulroney and former Quebec Premier Daniel Johnson for the Quebec government, looked at project plans for a new French-and English-language teaching hospitals. The French-language hospital (CHUM) would replace two existing hospitals, and the English-language hospital (MUHC) three. Each would be supported by an existing hospital facility to ensure ease of patient access.

The two-man panel was mandated to evaluate the plans against the parameters that they should not exceed budgeted costs of $\$ 1.1$ billion apiece, and not increase existing operating budgets. They concluded that the only way the projects could meet these conditions is if the number of beds in each new superhospital was reduced to a maximum of 550 with additional beds in the auxiliary hospitals. It was planned to have 608 beds at the MUHC superhospital, and 700 at $\mathrm{CHUM}$. 
In New Brunswick, the Department of Health and Wellness announced that 74 nursing students will benefit from the 2003-2004 Nursing Bursary Program. A total of $\$ 268,000$ will be awarded to student nurses and student practical nurses to help pay for their studies. The students who will receive bursaries will sign return-of-service agreements to work at a nursing home or a Regional Health Authority in the province. The bursary program was first announced in April 2001 as part of the province's three-year nursing resource strategy. Forty-seven of the students are enrolled in university nursing programs. Twenty-seven are studying at New Brunswick Community Colleges and will graduate as Licensed Practical Nurses (formerly known as Registered Nursing Assistants). Students will receive bursaries of between $\$ 1,000$ and $\$ 5,000$, depending on their field and the number of years they have committed to working in the province. This is the second year money has been issued in the bursary program.

The province has also created an Education Subsidy Program for Student Nurse Practitioners. The program encourages nurses to pursue their careers in New Brunswick as nurse practitioners. The government has approved $\$ 70,000$ specifically for student nurse practitioners to help cover their tuition fees and books for fall 2003 and winter 2004 semesters. A total of 21 student nurse practitioners benefit from the program; 4 from Université de Moncton, 16 from the University of New Brunswick, and 1 New Brunswick student attending Athabasca University in Alberta. In 2002, legislation provided for the creation and registration of nurse practitioners, and also enabled front-line nurses to fully utilize their skills in delivering primary healthcare services to the citizens of New Brunswick.

\section{Appointments}

Terry Durette has recently joined MDI Solutions as its new Vice President of Sales and Service.

The Ontario Hospital Association has appointed Rosalind Smith to the position of Vice-President of Member and Professional Relations (M\&PR) effective immediately. Ms. Smith has been with OHA for six-anda-half years as Director of Member Relations and is currently interim Vice-President of M\&PR. She will be responsible for a variety of member and professional

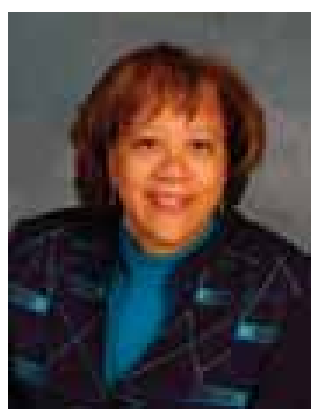

issues, such as supporting the work of the Governance Committee, Regional Council Executive Committees, the Professional Advisory Committee of the Board, Hospital Report and Patient Satisfaction and the Patient Safety Support Initiative.
Nova Scotia's 2004 budget includes a 10.9\% increase in health spending from what was originally in the 2003-04 budget. It is being paid for in large part by increases in corporate and personal taxes. The $\$ 230$-plus million increase in the new $\$ 2.3$ billion health budget includes $\$ 79$ million more for hospitals and $\$ 86$ million more for physicians' services. Long-term care is getting \$24 million extra, and as of next January, seniors living in nursing homes will no longer have to help pay for their medical costs. This advances the government's promise during the election to phase out the nursing home fees over a three-year period.

Newfoundland's Minister of Health and Community Services recently confirmed a new direction for provincial health and community services as outlined in the province's 2004 budget. The series of health reforms, aimed at protecting the sustainability of a publicly funded system, will create a foundation for safe, quality and accessible health and community care.

The four key initiatives include:

- Creation of regional integrated health authorities. Board integration will occur in the coming months, providing integrated and smaller corporate structures to better reflect the population base of the province.

- Development of a Location of Services plan to bring a balance of quality, accessibility and sustainability to the health services delivery system. Provincial standards will be developed to protect and ensure quality patient care, protect accessibility to care and ensure health authorities make evidence-based decisions to meet the health needs of each region.

- Development of a skill mix framework to ensure health and community services employees practice to their highest level of training.

- Adoption of a best practices culture to continually evaluate the programs and services we currently deliver and build upon the achievements in other jurisdictions.

Initiatives will be rolled out over the coming 18 months, beginning with a new structure for regional integrated health authorities and the development of consistent provincial standards for health and community service delivery.

The Canadian College of Health Service Executives (CCHSE) Board of Directors recently announced that Donnor Tower, Chief Liaison Officer at the Capital Health Authority in Edmonton is now Chair of its Board of Directors.

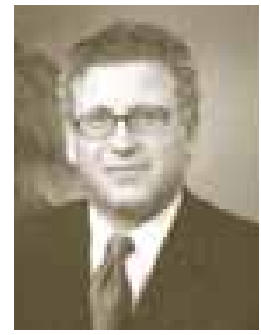

Joseph Mapa, President and Chief Executive Officer (CEO) of Mount Sinai Hospital in Toronto, is Vice-Chair.

Their two-year terms of office begin on May 30, 2004 


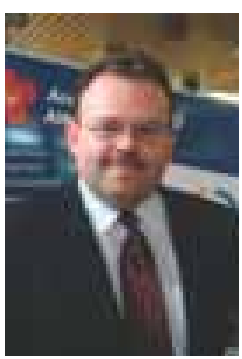

Angelo Presta has been appointed Cambridge Memorial Hospital's (CMH) Director of Clinical Support Services, effective April 7, 2004. He will assume a newly created portfolio at $\mathrm{CMH}$, which will include Admission/Discharge Planning, Allied Health, Clinical Education and the Scheduling Office. He has over 15 years of healthcare management experience. During the past four-and-a-half years, he has been the Assistant Executive Director, Corporate Planning, at the Hôtel Dieu Health Sciences Hospital in St. Catharines.

Following an extensive national executive search, the Board of Directors of The Scarborough Hospital (TSH) announced the appointment of Dr. Tom Ward as President and CEO of TSH, commencing June 1, 2004. A health care systems strategist and former paediatrician, Dr. Ward is currently the Deputy Minister of Health in the Nova Scotia Department of Health, where he was instrumental in establishing nine new District Health Authorities. The Board also announced that Glenna Raymond has accepted the position of Deputy CEO and Chief Operating Officer (COO). She joined the hospital in 1986, and most recently, she served as President and CEO at TSH, with a mandate to lead the recovery and revitalization of the hospital post-SARS. Prior to that appointment, she was Senior Vice President responsible for patient services, nursing and professional practice, and corporate planning.

\section{St. Joseph's Health Centre in Toronto} has appointed Ken Deane to the position of President and CEO, effective August 1, 2004. Mr. Deane is currently President and CEO of Hotel Dieu-Grace Hospital in Windsor. He also serves on the Operations Steering Committee of the JPPC and chairs the Hospital Funding Formula Committee.
Dr. Judith Shamian,

Executive Director, Office of Nursing Policy, Health Canada will be leaving Health Canada on June 11 , 2004. The Victorian Order of Nurses (VON)

Canada has appointed

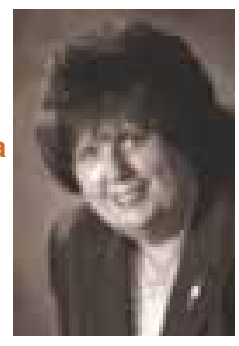

Dr. Shamian to be its President and CEO. Dr. Shamian has been Executive Director at Health Canada for nearly five years. Sandra MacDonald-Rencz has agreed to act as Executive Director in the interim.

\section{The Council of the College of}

Registered Nurses of Nova Scotia recently announced the appointment of Linda Hamilton, MN, RN, as the new executive director of the College, effective immediately. Ms. Hamilton is a graduate of the Bachelor of Science in Nursing program from the University of the Philippines and holds a Master of Nursing degree from Dalhousie University. During her 14 years with the College of Registered Nurses, she has held positions such as education consultant and manager of professional practice and policy services, and been project leader of a number of major initiatives supporting the College's policy priorities in education, legislation, primary healthcare and nursing leadership.

\section{The GTA/905 Healthcare Alliance}

Chair Jane Watson recently announced the appointment of Tariq Asmi to the position of Executive Director effective May 3, 2004. His appointment follows an extensive recruitment effort, and he replaces former Alliance Executive Director Joe Pilon who accepted the position of President and CEO of Espanola General Hospital and the Blind River Health Centre several months ago.
March 1, 2004, Brendan Seaton was appointed the Chief Privacy and Security Officer for Ontario's Smart Systems for Health Agency (SSHA). SSHA provides a secure, shared information technology infrastructure to make healthcare professionals more effective by giving them quick and secure electronic access to information to make better decisions for patients.

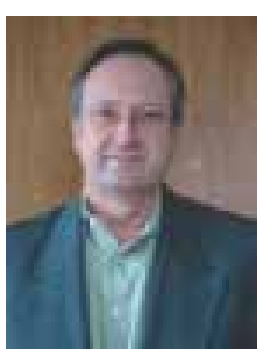

Nova Scotia's Department of Health has created a new chief health human resources officer to coordinate health human resources planning and Dr. Peter

Vaughan has accepted the position. Nova Scotia is the first province to establish a leadership position to coordinate its planning. As part of his responsibilities, Dr. Vaughan will work with other provincial health departments to develop an Atlantic approach to health human resources. Dr. Vaughan has been president of the Canadian Medical Association and for two years was director of health services for the Nova Scotia Workers Compensation Board. He has experience with varied health organizations and has had both national and international appointments. He has also worked on several projects that involved implementing changes affecting a number of organizations.

Susan Law was recently appointed the new Director of Research Programs of the Canadian Health Services Research Foundation (CHSRF). Law has extensive experience as a health service manager in both Canada and the U.K. and as a senior scientist and consultant researcher. She is scheduled to complete her PhD through the London School of Hygiene and Tropical Medicine in 2004. 
Canada Health Infoway has appointed Trevor Hodge as its Vice-President, Investment Strategy and Planning. Trevor will be responsible for leading strategy development in line with Infoway's business objectives. As Vice-President in this key position within the organization, Trevor will be instrumental in setting the direction for future investment decisions. He will also establish and maintain relationships with public and private sector stakeholders for the purpose of strategic planning.

Trevor has over 25 years of experience in the public health and health information technology sectors. Most recently, he was Partner and Corporate Health Practice Lead at Sierra Systems Group based in Seattle. He has also held senior positions at Alberta Health including that of Chief Information Officer and Acting Assistant Deputy Minister, Public Health. Trevor brings to Infoway in depth knowledge of health infostructure, electronic health records, and health surveillance systems.

\section{Vendor News}

\section{M innovations boost healthcare}

\section{M Introduces Lightweight Stethoscope}

$3 \mathrm{M}$ has launched the $3 \mathrm{M}^{\mathrm{TM}}$ Littmann $^{\mathrm{TM}}$ Lightweight II S.E. stethoscope. The unique bell/diaphragm chestpiece design on the stethoscope allows for better orientation around blood-pressure cuffs and body contours, and provides clear, reliable acoustic performance. In addition, the patented 3M Littmann Snap Tight Soft-Sealing Eartips provide a comfortable fit and more secure seal to reduce ambient noise and improve acoustics. For more information, visit www.3m.ca/ca/healthcare

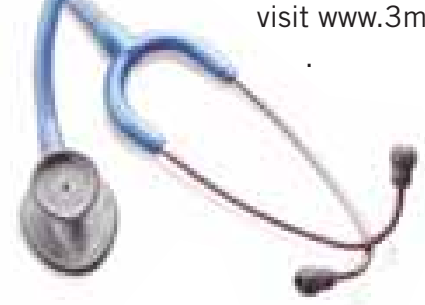

3M and MedMined Join Forces to Help Hospitals Reduce the Human and Economic Cost of Infection

3M Healthcare and MedMined Inc. will provide hospitals with the insight needed to target infection control initiatives and the practical solutions needed to improve patient and business outcomes. MedMined combines patented artificial intelligence technologies, clinical expertise, quality improvement training and outcomes measurement into a comprehensive service that reduces the incidences of healthcare-associated infections.

Using the data and insights generated by MedMined, the 3M Perioperative Consulting team will apply a systematic, evidenced-based quality improvement approach to the perioperative process. For more information, visit www.3m.com.
Revolutionary Alternative to the Traditional Surgical Scrub

3M has launched Avagard CHG Hand Antiseptic - the first waterless, brushless, surgical scrub. According to recent $C D C$ Guidelines, as many as $85 \%$ of nurses give a history of having skin problems. Frequent and repeated use of hand-hygiene products, particularly soaps and other deter-

gents, is a primary cause of chronic irritant contact dermatitis among healthcare workers. Avagard CHG alleviates this problem with its unique combination of chlorhexidine gluconate (CHG) and ethyl alcohol, which enables it to provide bacterial kill while the emollient-rich lotion helps maintain the integrity of the skin. Avagard CHG Hand Antiseptic utilizes a closed-system foot pump delivery system thus preventing contamination of the dispenser and recontamination of the hands. For more information, visit www. $3 \mathrm{~m} . \mathrm{ca} / \mathrm{ca} / \mathrm{healthcare}$ to chronic skin and wound care management. 3M Wound Coach will not only facilitate best practice guideline patient outcomes, but will also provide continuing professional development for clinicians to sustain those practice changes. For more information, visit www. $3 \mathrm{~m} . \mathrm{ca} / \mathrm{ca} / \mathrm{healthcare}$

\section{M Delivers Wound Coach}

Wound Coach will enable hospito develop a seamless, interdisciplinary, team-oriented, best evidence/

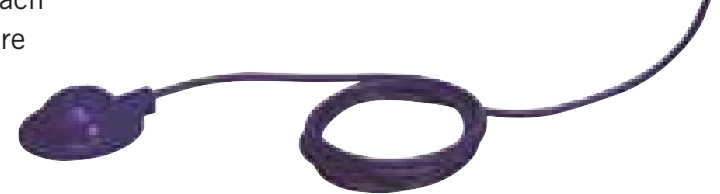

\section{GE Medical Systems Information Technology has a new name and a new boss}

GE has acquired British life sciences giant Amersham plc, and made its former CEO, Sir William Castell, president and CEO of a new entity named GE Healthcare. Headquarters are in Chalfont St. Giles, United Kingdom. GE Medical Systems Information Technology is now named GE Healthcare Technologies, and Joseph Hogan, senior vice president, now reports to Mr. Castell.

For more information go to: www.gehealthcare.com/portal/ news/pr_9642.html. 


\section{Misys signs Declaration of Support for "Partners for Patients Initiative}

Misys Healthcare Systems has joined the American Academy of Family Physicians in its goal to provide quality electronic health record (EHR) products to family physicians.

Misys Healthcare Systems signed a Declaration of Support for Partners for Patients, an initiative in which healthcare IT vendors work with the AAFP to ensure that patients receive the timeliest, most appropriate and most efficient medical care possible. As part of this initiative, the AAFP stresses the need for quality EHR solutions that meet four principles - affordability, compatibility, interoperability and data stewardship in the hands of the physicians. For more information, visit www.misys.com.

\section{Agfa and Evolved Digital Systems Come Together to Deliver an IMPAX Integrated Solution}

Agfa, a leader in digital imaging solutions, and Evolved, the first Managed Services provider in the diagnostic imaging market, have announced that McKenna Memorial Hospital, a 132-bed acute care facility serving the 36,000 residents of New Braunfels, Texas, has implemented a community-wide digital solution that will see the RadWeb ${ }^{\circledR}$ technology from Evolved implemented as part of an Agfa IMPAX ${ }^{\circledR}$ integrated solution. Via the Internet, RadWeb enables physicians and radiologists rapid and secure access to radiology images and reports, as well as the full patient exam status. For more information, visit www.agfa.com.

\section{Ainsworth Announces Total Plant Maintenance Performance Savings for Customers}

Ainsworth Inc. announced that its Total Plant Maintenance Program (TPM) brought substantial cost savings for Brampton-based Almag Aluminum Inc. At the end of the first year of Ainsworth Inc. managing Almag's entire maintenance program, maintenance costs were reduced by $23.6 \%$ over the previous year and $14.6 \%$ below this year's plan.

\begin{abstract}
Ainsworth's TPM program is an outsourced management program for medium to large manufacturers, designed to reduce an organization's costs of operations and increase production system efficiency. For more information, visit www.ainsworth.com.
\end{abstract}

\section{Cardinal Health Granted ISO 9001:2000 Certification for Pyxis Products}

Cardinal Health, Inc. announced its successful achievement of ISO 9001:2000 certification from ISO registrars DNV for its Pyxis automation products.

ISO, a Switzerland-based organization, comprises the national standards institutes' network of 148 countries whose delegates preside over standards that meet both the requirements of business and the broader needs of society. This certification covers all U.S. design and manufacturing operations, customer services and global sales for Pyxis automation products from Cardinal Health. For more information, visit www.cardinal.com.

\section{MediSolution Announces Acquisition of $\mathrm{ClO}$}

MediSolution Ltd. has completed the acquisition of Conseillers Info-Orientes Inc. (ClO), a provider of integrated financial applications for service industries. CIO, developer of the VIRTUO ERP suite, has a strong market position in healthcare and public sector organizations, and a base of more than 175 customers that generated approximately $\$ 4$ million of revenue over the past year. The acquisition stems from a successful twoyear partnership whereby MediSolution was a reseller of CIO's financial and materials management systems to the healthcare industry. The transaction is valued at up to $\$ 5$ million. For more information, visit www.medisolution.com.

\section{Our readers write:}

"This link will be very useful for us."

- Head Librarian and Director of Learning Resources, Nicholas J. Schrup Library Clarke College, Dubuque IA

"Thank you very much!"

- Electronic Resources, University of Manitoba Libraries

"The electronic subscription works fine. I have forwarded the details to our tutors." - Systems Librarian, Te Rutoi-A-Tini Malcolm Murchie Library, Waiariki Institute of Technology, New Zealand

Give every nurse, everywhere an opportunity to participate. Anytime. Enterprise-wide subscriptions - no log-in and no password required.

For more information contact Susan Hale E-mail: shale@longwoods.com 